\title{
Recitações: Bandolim de Adília Lopes
}

DIANA DUARTE FERREIRA

Universidade Nova de Lisboa

\begin{abstract}
Borrowing the notion of "projet d'ensemble" from Roland Barthes's Critique et verité, this essay proposes a critical analysis of Adília Lopes's Bandolim (2016). Two of the procedures that configure the book's interior are outlined on the cover: text as sound and text as image. The metaphor of the mandolin and its performative demands relates to Eliot's ideas about tradition and individuality and describes Lopes's approach to poetry. Through a close reading of poems in the collection, I argue that Bandolim performs on the infinity of unity while representing the unity of infinity.
\end{abstract}

Keywords: Projet d'ensemble, critical poetry, paronomasia, binomial, representability

“A arte tem também o carácter duplo dos símbolos: é e representa. Mas sucede que o que representa tem o interesse específico de ser representado do modo que é e não doutro" (Pimenta 11).

Bandolim (2016) é como irmão do meio de Manhã (2015) e de Estar em casa (2018). Os três livros integram a coleção "poesia inédita portuguesa" da editora Assírio \& Alvim. São como o tipo de irmãos cujo parentesco se induz mais facilmente a partir de gestos em comum do que pelo semblante. Do semblante assinala-se a presença de fotografias do passado da autora, no interior dos livros, com e sem a sua figuração: Manhã e Estar em casa contêm, cada um, quatro fotografias, Bandolim dezassete. Da mesma forma, o gesto comum que primeiro salta à vista na escrita é o registo memorial, mais que biográfico: embora o suporte das memórias seja a biografia, estas são selecionadas e dirigidas de 
acordo com focos orientadores que a ultrapassam na maioria dos casos. De entre esses focos destaca-se a linguagem.

O estudo comparativo do conjunto formado pelos três livros encontra-se, porém, à margem deste texto, cujo foco é Bandolim. O que se pretende, então, é apresentar o livro enquanto "projet d'ensemble" (Barthes, "Critique" 42). Não encontrando, muito simplesmente, o sentido que resolve o livro, mas procurando sentidos na aceção de direções e posições tomadas: para onde tende a aproximarse e de onde a distanciar-se, o que nega e afirma, de que formas opera o livro estes movimentos. Tal não exclui a possibilidade de referência aos irmãos de Bandolim, ou, na verdade, a seja o que for: mesmo porque Bandolim é constitutivamente citacional e situacional, invocando com regularidade o exterior para o interior do livro. Além de um semblante mais carregado de fotografias, em comparação com o dos irmãos, também a sua escrita parece a mais iminentemente fotográfica. Mas a este texto só compete observar como pode ser iminentemente fotográfica e não como é a escrita mais iminentemente fotográfica dos três livros. De todo o modo, tornar hermética a discussão de um livro onde recitar é um gesto contínuo seria, além de uma traição a priori do projeto de conjunto, simplesmente impossível.

"Gosto de coisas e de nomes. Gosto de nomes próprios" (Lopes, "Bandolim" 212). A capa de Bandolim, através de dois dos seus elementos, título e desenho, é ponto de partida e chegada deste texto. O título é o nome atribuído pelo autor ao projeto de conjunto que a obra representa. É o elemento que permite identificar e referir o texto, o que lhe confere existência jurídica e é indissociável do seu fundamento ontológico. Por isso, e porque os nomes têm preponderância no livro, é importante partir do princípio que se trata de um elemento relevante, quiçá revelante. Relativamente ao desenho da capa parte-se do mesmo princípio. Embora o facto não tenha a devida menção editorial, a autoria de Adília Lopes reforça o carácter intencional do desenho enquanto gesto de representação do livro.

Existem diferentes tipos de bandolim, moldados de acordo com a zona, cultura e idioma musical, o que evidencia a proliferação e versatilidade desse instrumento. É claro que certos traços são estruturais e comuns a todos os bandolins: em particular, os que lhe conferem o timbre característico. Entre eles, destaco o facto de o bandolim ser um instrumento de cordoamento duplo, tal como a guitarra portuguesa. As quatro ou cinco cordas estão dispostas em pares, 
sendo na verdade oito ou dez. Isto significa que duas cordas funcionam como uma só, soando em uníssono: quer na aceção mais comum do termo, a de simultaneidade, quer na de intervalo resultante entre duas notas com a mesma frequência ou afinação. Assim, deparamo-nos com uma ideia de confluência de cordas ou de vozes que vibram a mesma nota na mesma altura (nas aceções de instante e de frequência): $2=1$.

Todavia, na prática, a consonância ideal é bastante instável e dependente de inúmeros fatores. Basta notar que é do senso-comum que os instrumentos de cordas devem ser afinados com regularidade. Mas nem isso garante a afinação; por mais robusto e nobre que o instrumento possa ser, a elevada sensibilidade da madeira a variações de temperatura e humidade transforma-o numa espécie de barómetro. (O poema "Barómetro" [143], a propósito, é retomado na página 90 deste texto.) A qualidade e o nível de desgaste das cordas, bem como o tocar propriamente dito, também concorrem enquanto fatores críticos contínuos de desafinação. "Calculo cada passinho ao Ångström" (35): os afinadores do instrumento rodam-se minuciosamente, mas a afinação ideal pode não ser de todo possível. O resultado da desafinação será, em todo o caso, uma manifestação dissonante da consonância. A tensão auditiva é provocada por diferenças de afinação. Mesmo que à partida (corda solta) sejam mínimas, ao longo do braço tornam-se cada vez mais conspícuas, ou menos ignoráveis, ao ponto de colocarem em causa qualquer possibilidade de harmonia.

"Gosto mais dos ABBA do que de Wagner. Mas também sei gostar de Wagner" (88). Embora característico de vários folclores e da cultura popular em geral, o bandolim não deixa de ocupar um lugar cada vez mais representativo na música erudita, quer na vertente clássica, onde a composição é primeiro fixada na escrita e depois interpretada lendo a partitura, quer na vertente mais idiossincrática do virtuosismo artístico, em que a composição acontece no momento (improviso), mais ou menos inspirada e dentro de uma forma mais ou menos fixa. Essa forma é muitas vezes popular, mas também parte com frequência de temas clássicos, de ideias súbitas ou de motivos tirados de ouvido. Funciona como plataforma performática onde confluem o domínio técnico do instrumento e o domínio teórico do sistema musical em geral. Determinantes nesta confluência são o conhecimento das tradições idiomáticas, a memória e o cálculo. Um músico deve ser uma espécie de mestre em análise combinatória; de 
outro modo, ser cópia do outro e de si mesmo será sempre mais uma condição do que um risco.

Tratando-se de um instrumento harmónico, o bandolim permite, por um lado, a execução de linhas melódicas e, por outro, a execução de progressões harmónicas. O que idealmente se pretende, sobretudo a solo, é a execução simultânea da melodia e da harmonia. A junção, traduzida em música, é já um exemplo de virtuosismo ou de forte aspiração. De novo, 2 = 1: além do domínio da performance, que se constitui pela conjugação do domínio da música e do instrumento, ainda a complexa gestão binomial que o domínio do instrumento envolve e exige. É este tipo de organicidade que abre o infindável leque de combinações e possibilidades performáticas. A expressão individual é fundamental, mas perante a imensidão que é desejável incorporar - e transformar-, o músico só pode, paradoxalmente, render-se. Na escrita, tal como na música e na arte em geral, a tradição não pode ser herdada, mas apenas obtida a custo de muito esforço, estudo, dedicação e disciplina: bem ao encontro da ideia exposta no ensaio "Tradition and the Individual Talent" (1919) acerca da perceção da simultaneidade entre passado e presente. T. S. Eliot sugere uma espécie de organismo vivo e dinâmico formado por toda a poesia e deixa uma imagem de impessoalidade muito semelhante à que delineei com as ideias de virtuosismo e análise combinatória:

[...] the mind of the mature poet differs from that of the immature one not precisely in any valuation of "personality," nor being necessarily more interesting, or having "more to say," but rather by being a more finely perfected medium in which special, or very varied, feelings are at liberty to enter into new combinations ... the poet has, not a "personality" to express, but a particular medium. (par. 15)

Ao referir um instrumento, o título indicia desde logo uma dimensão musical que convoca as dimensões acústica e acusmática. No mapeamento deste projeto de conjunto, que venho a esboçar como interartístico, verificaremos que o som é indissociável da paisagem em que o livro se retrata. A descrição das características do bandolim e do seu uso também não teria lugar neste texto se não se tentasse assim estabelecer uma relação de analogia entre a natureza do 
instrumento e a do livro. Como é que em Bandolim se vão afinando e desafinando as cordas duplas? Que tipo de repertório se domina e interpreta? Que registos tem o discurso e que interpretações faz de outros discursos, ou seja, como os transforma? Quais as características do seu timbre particular, quais as expressões idiomáticas predominantes? E etecetera: eis o tipo de questões que podemos colocar. No espaço da citação e da recitação confluem letra e intérprete, estejam ou não bem afinados na mesma nota. A este respeito, Eliot refere que o melhor trabalho de um poeta, a forma como consegue destacar-se dos restantes, pode coincidir com os momentos em que, na obra, os poetas mortos mais vigorosamente se fazem ouvir e afirmam a sua imortalidade (par. 2). Há algo de memorial nesta visão de Eliot, que termina o ensaio propondo que o poeta viva no "present moment of the past." Bandolim parece estar em consonância com a descrição eliotiana. São raras as páginas que não evocam o passado, citam livros, invocam autores ou parafraseiam dizeres. A atividade citacional conjuga-se com a atividade situacional: a memória e o contexto da sua fixação no presente estão ao serviço da representação, por sua vez palco performático da linguagem.

Na medida em que Bandolim evoca uma biografia, em simultâneo evoca as camadas de texto e discurso que integram momentos marcantes de uma vida intrinsecamente literária. Gostava, por isso, de salientar o papel decisivo (salvífico) da literatura em momentos críticos. Em Manhã podemos ler que a autora ganhou o primeiro prémio literário aos 11 anos. "Dois colegas meus gostaram da redacção. Tinha encontrado dois leitores ideais. Estava salva" (52). Neste exemplo, a salvação acontece à Adília escritora através do reconhecimento dos leitores. Mas em Bandolim o fenómeno repete-se com a Adília leitora, que se reconhece no livro. Em "2 livros," conta como, aos 21 anos, a leitura desses dois livros the salvou a vida, um porquê referia a existência do outro, qual abismo onde se cai para se ser salvo (Lopes, "Bandolim" 109). Em "Uma psicanalista" (120), relata uma impressionante experiência, da qual só consegue sair viva por ter lido Hansel e Gretel: "A literatura salvou-me sempre."

É importante observar como a atividade poética e a atividade crítica se conjugam no recurso à citação. Barthes refere essa conjugação, identificando-a como forte tendência literária desde Mallarmé- “a dupla função, poética e crítica, da escrita, sofre um intercâmbio, interpenetra-se e unifica-se" (Barthes, "Crítica" 43) - e descreve a citação como gesto de convergência (transmissão) constitutivamente divergente (redistribuição): "efectivamente a visão crítica 
começa no próprio compilator: não é preciso acrescentar algo de seu a um texto para 'deformá-lo.' Basta citá-lo. . . ” (72). Reconvertendo a tradição em nova matéria, lugar-comum a ser estranhado, forma mais ou menos fixa sobre a qual improvisa, Adília Lopes faz soar, em uníssono, poesia e crítica, fundindo ambas na performance literária. Em Bandolim, a dimensão sonora da escrita concorre com a dimensão poética do prosaico ("Fuzzy-felt" [65]):

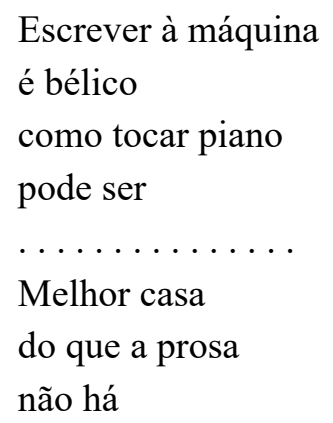

A atividade poética adiliana pode ser descrita como uma dansa em que norma e infração constituem par. "Minsk" (56) é um dos exemplos onde encontramos esse erro inequívoco, herança de Sophia, incorporado numa recitação de Emma Goldman: "Se eu não puder dansar, esta não é a minha revolução." $\mathrm{O}$ ' $\mathrm{S}$ ' tem um quindim gráfico que o 'Ç' não alcança. Estamos perante uma estética que se afina pelo significante, no que diz respeito ao som do signo e ainda à grafia que de todo o modo o fixa na materialidade da escrita. A dansa e a revolução, a poesia e a crítica, o som e o desenho, convergem no mesmo movimento divergente. Em Manhã encontramos "Dansar" (77): "Desde que comecei a dansar escrevo dansar com s. . . Enquanto danso, penso. Penso e giro. De girar e de gerir. Enquanto danso, raciocino e raciocino melhor. Enquanto danso, rezo pela paz."

"Minsk" também é paradigmático de outro procedimento frequente, mise en abyme. O primeiro texto referido remonta aos 11 anos da autora, que atualmente não se lembra do nome do autor e já não tem o respetivo livro. Ficou-lhe na memória, porém, o episódio do periquito oferecido a alguém que, não sabendo que nome lhe dar, abriu um mapa sobre a mesa e deixou que o periquito escolhesse o próprio nome, que dá título ao poema. Daí somos levados à presença da professora de português, que emprestou a Adília Platero e eu de Juan Ramón Jiménez, ainda hoje um "livro de cabeceira": "Dizia, quando eu tinha 11 anos, 
que eu havia de ser uma escritora conhecida." Aos 12 anos, trouxe da biblioteca O músico cego de Vladimiro Korolenko, que também se tornou "livro de cabeceira.” A sucessão de recordações literárias culmina num parágrafo não menos abismal, já que "Até aos 12 anos, não tinha encontrado na literatura portuguesa textos de que gostasse tanto. . . . Ainda não encontrei. Continuo na mesma. Só me lembro das cantigas de amigo." Observe-se como o serpentear por entre referências acústicas e musicais orienta a direção crítica do texto. Em evidência no título, o pássaro deixado em liberdade para escolher o próprio nome. O livro de cabeceira, tomado como objeto mágico a partir da profecia da professora, que se realiza. O título do outro livro de cabeceira, onde figura um músico. $\mathrm{O}$ facto de as canções de amigo serem os únicos textos de língua portuguesa onde a autora encontra semelhante magia.

Passemos ao poema que recita um verso de "Birds in the Night" de Luis Cernuda (152): "Mas de Verlaine não se recita nada porque não está na moda." Adiante, porém, encontramos uma recitação dos dois primeiros versos do poema de Verlaine "Art poétique": "De la musique avant toute chose, / Et pour cela prefere l'Impair" (168). O poema simbolista de 1874 canta a "chanson grise" da ambiguidade semântica, na qual o indeciso e o preciso se conjugam, e retoma, no final, a invocação da música: "De la musique encore et toujours!" O apelo à música é claro: deve estar em primeiro lugar e não ter qualquer tipo de constrangimento formal. Ainda a propósito de reflexões estilísticas, encontramos uma citação de Flaubert, em que este afirma que Buffon tomava os maiores cuidados para escrever, representando-o como o tipo de autor que apenas se preocupa com o estilo, ou modo de dizer as coisas (Lopes, "Bandolim" 137). À citação, a autora acrescenta que, para escrever, põe "na cabeça um lencinho de assoar de pano com Lavanda Ach. Brito." A ideia de estilo é literalizada de forma caricatural e kitsch, enquadrando a escrita numa mise en scène performática que o recurso ao tipo de figura de Buffon, caçoada por Flaubert, preparava desde o início. O nome da água de colónia é dividido por um ponto final, o que faz com que o texto seja concluído com uma afirmação: "Brito." — do sonoro verbo britar. A autora termina o poema sumarizando a própria atividade poética num gesto reflexivo e sinónimo de moer e remoer, desconstruir, decompor, simplificar, que exige um esforço paciente, em detrimento do ornamento e estilização constantes. É a partir desses grãos que o poema se faz: podemos ler, em "Modus operandi," que "Grão a grão, verso a verso, enche a galinha o papo" 
(19). No entanto, outra corda vibra a par com esta. A locução "britar a palavra" quer dizer, justamente, "faltar à palavra dada" (Houaiss 665). O texto também termina negando a cena com que se afirma, ou que afirma para poder rejeitar. Nomeadamente, negando o que a performance tinha, à primeira vista, de ornamento e espalhafato.

"On ne dit pas... On dit..." (77) apresenta duas colunas de palavras. A coluna da esquerda é composta por palavras que não se devem dizer (estrangeirismos), e a da direita mostra as palavras que se devem dizer em detrimento das anteriores.

$$
\begin{array}{ll}
\text { não se diz atelier } & \text { diz-se oficina } \\
\text { não se diz dossier } & \text { diz-se arquivador } \\
\text { não se diz placar } & \text { diz-se expositor } \\
\text { não se diz envelope } & \text { diz-se sobrescrito } \\
\text { não se diz soutien } & \text { diz-se estrofião }
\end{array}
$$

Os primeiros quatro versos criam, através do léxico oficinal, uma estabilidade que o quinto verso, referindo uma peça de roupa interior feminina, destrói. A ruptura precipita a conclusão do poema, num último verso, já fora da dinâmica das colunas: "estrofião só pode ser um palavrão." A palavra, proveniente do grego antigo $\sigma \tau \rho o ́ \varphi o \varsigma$, partilha com 'estrofe' o étimo remoto 'estrof(o)' que significa "torção" (Houaiss, 1641). Mas em que sentido é que estrofião só pode ser um palavrão, não se tratando de "palavra grande e de pronúncia difícil"? No sentido de "expressão pomposa e empolada" ou no sentido de "palavra grosseira e obscena" (2730)? Seja como for, 'estrofião' é palavra tida pela autora como impropriedade. A ideia de liberdade de escolha, em particular de escolha do sinónimo com o significante mais consonante com o significado, independentemente da origem da palavra, é imediata. O autor é um pássaro deixado à solta sobre o mapa da linguagem e vai pousando em nomes como se levantasse voo. O tom disfemístico do verso parece sugerir que o significante português retrata, ao contrário do francês, o lado opressivo de um objeto que, vinculado a um género, é tomado como essencial. Tal como a estrofe, na arte poética... - recordo que em "Fuzzy-felt" (65) a prosa é dada (em verso) como a melhor casa. O facto de 'estrofião' só poder ser um palavrão e de, ainda assim, não poder desvincular-se do significado para o qual remete, chama a atenção para 
as características grosseiras e empoladas de um objeto que em outra língua é apenas desejável.

A importância do som e da imagem na estética adiliana liga-se ao que passo a designar como poética do significante. Novamente, $2=1$. Recria-se o signo linguístico estabelecendo uma relação causal de consonância variável entre as suas faces. Alguns exemplos sonoros: "Nos anos 90, em Lisboa, disse-me que, numa língua africana de Angola, crocodilo diz-se djalanga. Acho uma palavra muito boa para crocodilo. Crocodilo também é uma palavra muito boa para crocodilo" (48). Fica claro que 'djalanga' e 'crocodilo' são palavras cujo significante e significado estão em consonância. Em "Lujubre" (54): "Uma amiga minha contou-me que, em criança, quando lia romances e via a palavra lúgubre, pensava que se pronunciava lujubre. Acho que tinha razão. As coisas lúgubres são lujubres." Em "Bee" (59): "Afugento as abelhas pronunciando bee com força mas baixinho. As abelhas afastam-se sempre. Experimentei fazer isto e tenho tido uma taxa de sucesso de $100 \%$. Talvez seja por isto que abelha em inglês se diz bee." Tanto a razão de ser do erro, no caso de "Lujubre," encontrada a partir da reflexão que a estranheza do som provoca, como a expressão "talvez seja por isto," no caso de "Bee," evidenciam uma maneira causal de pensar as duas faces do signo. Barthes também descreve a literatura como "exploração do nome: "No fundo, o escritor, intimamente, acredita que os signos não são arbitrários e que o nome é uma propriedade natural da coisa" (Barthes, "Crítica" 50). Em Bandolim, vários exemplos comprovam que Adília aprecia e incorpora esta prática ${ }^{1}$.

O gosto, determinante na construção da identidade literária e, claro, na elaboração de poesia crítica, é várias vezes discutido. "Uma doente internada no Júlio de Matos disse-me: 'Não tenho gostos.' É horrível” (126). Observemos o gosto especial que Adília demonstra pela paronomásia, figura cuja natureza sónica a torna representativa da poética do significante. Mais do que extrair expressividade da combinação de palavras que apresentam semelhança fónica (e/ou mórfica) mas possuem sentidos diferentes, julgo que a paronomásia permite, através do significante, uma aproximação metafórica original de realidades aparentemente distantes, concatenadas num ponto quiasmático de consonância semiológica. Em "[Orgulho. Gorgulho.]” (15), que alude à comédia

\footnotetext{
${ }^{1}$ Outros exemplos nas pp. 16, 49, 56, 121, 212.
} 
de Plauto, é pelo som que se chega à metáfora parasítica, neste caso, ou ao ponto onde orgulho e gorgulho se cruzam. Mas o ponto de encontro nem sempre é claro. Em "[Aspas]" (96) temos o par "aspas / caspas." Em que ponto se cruzam estes dois nomes, tendo em conta que versamos um livro repleto de citações e, portanto, de aspas? "São tristes / os trastes" (130). Que trastes? Os utensílios de pouco valor da casa, os indivíduos imprestáveis ou os trastes do bandolim? E que tristes? Pesarosos? Lamentáveis? Ou todos comoventes, à sua maneira? Em "Thanatos" (86) encontramos uma epígrafe retirada da canção dos Beatles "And I love her": "Bright are the stars that shine / Dark is the day" é mote da construção "The stars? The scars?" Amplificada pela paronomásia, a "chanson grise" faz-se ouvir.

É também a paronomásia que serve de base ao trocadilho, triquestroques ou calembour, com o qual o livro se inaugura em texto após as fotografias iniciais. Em "[Disse-lhe o cura então:-Confio em Deos.]" (13) podemos ler o último terceto de $A$ uns noivos que se foram receber, levando ele os vestidos emprestados, e indo ela muito doente e chagada, soneto de D. Tomás de Noronha. O cura diz "Confio em Deos," o noivo responde "E eu confio" e a noiva "E eu com fios," referindo-se não apenas às ligaduras, mas ao próprio corpo desfiado que as ligaduras encobrem. O efeito é de revolução, uma vez que o significante metamorfoseado tem efeito retroativo sobre os anteriores. Sendo todo o traje emprestado, o "confio" do noivo não pode deixar de remeter, ironicamente, ao ato de levar fiado. Mas é transformador, sobretudo, porque a noiva apela assim à crueza da realidade por detrás da performance ritual do matrimónio, desmascarando a representação e o fingimento que the são subjacentes. Corrompe o ritual pela recriação subversiva da palavra que esse mesmo ritual exigia para se concretizar. A força revolucionária do erro comprova-se, fazendo cair as máscaras de forma irreversível. Retomo assim o 'S' da dansa, metonímia de liberdade, de revolução e de som, lugares sibilantes da estética adiliana. Falta, fazendo a ponte entre as dimensões do som e da imagem, unir-lhe as pontas soltas e transformá-lo em lemniscata: do grego $\lambda \eta \mu v i ́ \sigma \kappa o s$, fita que pendia da coroa dos vencedores, a palavra é nome (lugar geométrico) e adjetivo (ornada de fitas).

"Tenho de acabar de escrever este livro. Assim é a escrita infinita. Gostava que este livro fosse uma bomba de balas. Balas em brasileiro, claro. Balas são rebuçados" (Lopes, "Bandolim" 153). A autora parece aqui definir o projeto de 
conjunto do livro; a mera sugestão de um potencial explosivo é sinestésica, estrondosa, dansável. "Brasileiro" é uma expressão informal que designa a variante brasileira da língua portuguesa. $\mathrm{O}$ gesto de quebra da ambiguidade da palavra 'balas'_-“em brasileiro, claro”- é performático: em brasileiro 'balas' também significam projéteis e, se o brasileiro não deixa de ser português, também em português significam rebuçados. A natureza da "bomba" é explodir, independentemente da sua feição mais ou menos doce. Em Manhã podemos ler: "Barthes escreveu já não sei onde cito de cor: o açúcar é violento. Acho que tem razão" (94). O gesto de desambiguação acaba sendo o oposto, e disfarça, sob o açúcar cristalizado, o fundo bélico ao qual a autora não pode deixar de recorrer, por mais que não se identifique com esse registo, precisamente para o combater através da escrita. Recuperamos a belicidade da escrita à máquina em "Fuzzy-Felt" (Lopes, "Bandolim" 65): "Não gosto de belicismo / mas gosto de escrever à máquina." Conto, entre as balas de Bandolim, diversas orações e apelos à paz: "armas desarmantes" (88), quem sabe ajudem a vencer a amargura do mundo. A escrita infinita nasce do desejo de contingência, movida pela determinação em materializar-se num objeto que possa, por outro lado, nunca ter fim, ou nunca parar de começar: o livro. ${ }^{2}$

Vários textos preservam a data, outros data e hora em que foram escritos. Quais as implicações da indexação do tempo no corpo do poema? Analiso o caso de dois poemas escritos no mesmo dia (22 mar. 2015) que parecem representar o mesmo contexto: "Ecclesia domestica (da parede para o caderno)" (25) e "[De manhã, no quarto virado a Leste]" (27). Embora uma visão de espelhamento entre ambos não possa deixar de ser conjetural, a poética do significante e a sua graça ambígua apelam ao reconhecimento e exercício dos prazeres lúdicos de leitura. Os rebuçados também são isso.

\section{Céleste c'est l'Est}

Esope reste ici et se repose

Zinnia de Puig

Ertilas

\footnotetext{
${ }^{2}$ Por exemplo: "Estamos a perder o mundo. É o Apocalipse. Resta-nos ir chuleando os trapinhos, os papelinhos, para que o mundo não se desfie todo de uma vez. Resta-nos desentropiar. Não estou a escrever um manifesto, estou a escrever uma oração" (141). Outros exemplos nas pp. 111, 131,151, 155, 158,176, 220.
} 
De manhã, no quarto virado a Leste, conto pelos dedos da mão direita as sílabas dos versos e as badaladas do sino de Arroios a dar as horas.

Os quatro versos de "Ecclesia domestica" compõem um retrato dos elementos visíveis no quarto, do ponto de vista da autora. O domínio da imagem é realçado pelo conjunto de versos, um a um sustentados pela poética do significante, nas suas vertentes gráfica e sonora. No primeiro verso, "Céleste c'est l'Est," produzse uma anáfora através de paronomásia, descrevendo o eco da paisagem celeste que se pode alcançar da janela do "quarto virado a Leste." É provável que o segundo verso, "Esope reste ici et se repose," se refira literalmente a um livro de Esopo. É um palíndromo, legível em ambos os sentidos, verdadeiro exercício de performance poética onde a ambiguidade do som é (e)levada à representação gráfica. O terceiro verso, "Zinnia de Puig," indicia um frasco de perfume. O quarto verso é "Ertilas," ou seja, o típico 'salitre' das paredes, com a ordem das letras invertida. Para clarificar o jogo:

1. Ambos os poemas começam com a mesma referência, a vista matinal para este.

2. O espelhamento do segundo verso indicia a reflexividade entre os dois poemas, como se um fosse sucedâneo do outro.

3. No terceiro verso, o som do nome é metálico como as badaladas.

4. A inversão da palavra, no quarto verso, é indicativa da possibilidade de se retratar de facto um espelho, pendurado na parede, refletindo o salitre de outra parede e, provavelmente, os restantes elementos representados.

Quando lemos que a autora conta pelos dedos "as sílabas dos versos e as badaladas do sino de Arroios a dar as horas," podemos induzir que se refere aos versos que em "Ecclesia domestica" retratam a parede; e que os dois últimos correspondem, em particular, a elementos da parede com o mesmo número de sílabas métricas que as badaladas que dizem as horas. Assim, obtemos seis sílabas $(4+2)$, seis badaladas, seis horas da manhã, o sol prestes a nascer celestial. 
O jogo de espelhos compõe o cenário performático de um ato de escrita binomial por natureza. Um "produto notável" (nome dado a certo tipo de expressões binomiais), elevando o literal à enésima potência: tradição e talento individual, poesia e crítica, representação e performance, significado e significante, som e imagem. "Para mim é tudo literal. Só acredito em traduções literais": é assim que a autora termina "A espada" (123). "Que farei eu com esta espada?" - eis a pergunta que o leitor pode colocar perante cada poema: ${ }^{3}$

$$
(a+b)^{n}=\sum_{p=0}^{n} \frac{n !}{p !(n-p) !} a^{n-p} b^{p}
$$

Suscitado pelo recurso a representações alheias ao uso comum da linguagem, o problema da legibilidade talvez descreva algumas das dificuldades inerentes ao discurso poético emancipado de normas poetológicas. Analisemos, em Bandolim, os casos mais conspícuos. Se partimos do princípio de que pelo menos alguns leitores não dominam certos conceitos matemáticos, devemos estender a questão aos vários textos citados em outras línguas e não traduzidos. $\mathrm{O}$ caso mais radical é um parágrafo de Tito Lívio, em latim (75). Seria ingénuo se a autora presumisse que todos os leitores entendem uma língua morta, por mais que se trate de um cenário ideal e que a página diga que está viva. Talvez esteja em causa outro tipo de ingenuidade, se em vez disso o projeto de conjunto parece sugerir que os gatos têm a capacidade de apreciar e deixar-se levar pelo som, em particular do latim e da música de Debussy: "Estudava latim com a minha gata Faruk. A Faruk não reagia ao francês que papagueava em voz alta, ao latim reagia e muito. . . . Nenhum bailarino humano conseguiria perceber tanto de Debussy como o Amorinhos.... Quem dera a tantos intelectuais saber tanto como a Faruk e o Amorinhos!" (183).

A persistência crítica do binómio animal e humano, na qual a aceção algébrica da palavra 'binómio' se cruza com a biológica, é notável ao longo do livro. Em "Carros" (53), lemos que "as pessoas dão importância a umas coisas

\footnotetext{
${ }^{3}$ O binómio de Newton, ou a mancha gráfica de "[Sou o binómio de Newton de Fernando Pessoa]"
} (210). 
que não valem um caracol": literalmente não chegam a valer um caracol, encarnação da espiral logarítmica. "De Consoada [...]" (43) traz-nos um soneto de D. Francisco Manuel de Melo e em rodapé uma nota da autora: "Gosto muito deste soneto. . . . Mas não gosto que diga mal dos perus e dos porcos. Não há pássaros vulgares e os porcos não são porcos." Deparamo-nos, em "Sexo" (115), com a designação binomial "animais não humanos." Têm, em comum com os animais humanos, o facto de o sexo ser "supercomplicado." O lado animal deve ser sempre tido em conta, sobretudo porque o amor não é exclusivo dos animais humanos. Pelo contrário: em Estar em casa podemos ler, na descrição da morte da gata Lu: "Acho que só os animais são capazes de amar assim tanto" (79). A alienação das pessoas rasura o amor e dá como natural o que não é, invertendo princípios que poderiam constituir um mundo menos bélico e mais justo. As preocupações pessoais da autora tendem, afinal, para uma universalidade a haver; e as situações biográficas tendem a ser convocadas em quadros cuja abrangência cruza sempre várias fronteiras: "A minha mãe era bióloga. Dizia: «O que mata bichos mata pessoas.» As pessoas esquecem-se que são bichos" (Lopes, "Bandolim" 32).

Em "[Sou o binómio de Newton de Fernando Pessoa]," a fórmula está na página para ser apreciada. Mas é uma estética metonímica, onde através do literal se pode aceder à beleza paradoxal do infinito contingente, à síntese de um conceito que é da ordem do inumerável. A fórmula concatena a possibilidade de expansão infinita de um produto notável $(\mathrm{a}+\mathrm{b})^{\mathrm{n}}$. Quando $n=0$, o resultado do binómio é 1 . Se $n=1$, o resultado é a $+\mathrm{b}$. Se $n=2$, o resultado traduz-se na expressão $a^{2}+2 a b+b^{2}$. Se $n=3$, então temos como resultado, usando a propriedade distributiva, a expressão $a^{3}+3 a^{2} b+3 a b^{2}+b^{3}$. E assim sucessivamente: a partir de $n>3$, as expressões tornam-se cada vez mais complexas. O binómio de Newton permite escrever, na forma canónica, o extenso polinómio correspondente à potência a que é elevado o produto notável. Usado sobretudo nos casos em que $n$ assume valores elevados, também não deixa de ser, figurando num livro de poesia, uma forma potencialmente ilegível de representar quer a simplicidade enquanto possibilidade de síntese do infinito, quer a mestria que sustenta a criação dessa possibilidade. A parte da fórmula correspondente à fração (onde estão os pontos de exclamação, factoriais ${ }^{4}$ ) é

\footnotetext{
${ }^{4}$ Outros poemas com factoriais nas páginas 209 e 217.
} 
equivalente à expressão combinatória $\left(\begin{array}{l}n \\ p\end{array}\right)$, que diz respeito ao número possível de combinações $(p)$ num dado conjunto $(n)$. Este é o tipo de cálculo utilizado no ramo da genética, em que $n$ representa o número de poligenes que concorrem na formação de determinado traço fenotípico. Não deixa de ser curioso que a autora se retrate a partir deste binómio de Newton e, por intermédio, de Fernando Pessoa, uma vez que todos os exemplos citados em Bandolim concorrem para o $n$ adiliano. $O$ conjunto das tradições artísticas e científicas colabora na elevação combinatória dos diversos binómios da autora.

Porque o nome de Fernando Pessoa concatena mais possibilidades, seria diferente se Adília - "eu, que ao fim e ao cabo devo ser a Fernanda Pessoa, modéstia à parte" (180) — escolhesse retratar-se como o binómio de Newton de Álvaro de Campos, designado por Pessoa autor do poema que Adília recita. De acordo com o poema, constatamos que o problema é pouca gente reparar que o binómio de Newton é tão belo como a Vénus de Milo. Isso acontece, sobretudo, porque pouca gente consegue ler ou traduzir o que significa. Assim, neste caso, o problema da legibilidade relaciona-se com a possibilidade de representação do ilegível que se pretende afirmar: a própria beleza, não compreendida pelos códigos em vigor. Ler-se a si mesma como exemplo de beleza implica que se assuma adepta de uma estética imposta como marginal e, como veremos, confinada a uma ideia de passado. Assim, em "Pessoa e o binómio de Newton (à suivre)" (211), o fenómeno estende-se ao poema de Campos, que não pode continuar a ser lido da mesma maneira: segundo os códigos atuais, "neste tempo de vacas magras / até a Vénus de Milo é uma gorda obesa." Enquanto o poema anterior, em que a autora se retrata num apagamento hiperbólico, parecia subscrever a ideia de que a Vénus de Milo é bela, o poema "à suivre" reconfigura tal ideia como anacrónica. E se a Vénus de Milo é hoje considerada, além de "uma gorda obesa," "uma criminosa / a precisar de banda gástrica / e de xilindró," então a expressão matemática deve representar, além da síntese do infinito, o confinamento sistemático, no que isso tem de poética e de crítica. O poema de Campos passa a sofrer, tal como a autora, os efeitos provocados pela tensão inevitável entre poéticas constitutivas de tempos diferentes. Nomeadamente, o de ser confinado a um tempo que acabou pela mesma recitação que o devolve ao presente. Com a Vénus de Milo deposta da equação, o binómio de Newton passa a ser tão belo quanto a ausência de beleza. Cindidos, à suivre, entre a perenidade 
da metáfora da beleza ilegível e a efemeridade dos critérios de ilegibilidade da beleza, poema e autora são retroativamente reunidos enquanto produto notável dessa cisão: metáfora e autorretrato. Em "O meu retrato" (161), a descrição do retrato da autora, feito no tempo em que ainda se tiravam retratos em lojas, fazse somente pela ausência da montra onde então não teve o privilégio de figurar, e onde ainda hoje as "fotografias estão róseas ou amarelecidas." Mas o retrato da loja, dividida entre o passado fotográfico que sobrevive na montra detalhadamente anacrónica e o presente das fotocópias que assegura a sobrevivência do negócio tornando o fotógrafo obsoleto e desnecessário, ocupa esse lugar de ausência e passa a defini-lo como zona de descontinuidade, ângulo morto esquadrinhado pela escrita.

“A cor do princípio dos anos 70 era um amarelo fabuloso" (41). Todo o tempo tem uma cor que o próprio tempo vai comendo. O mesmo se passa com as memórias e com as fotografias (138). A presença que registam torna-se cada vez mais fantasmagórica; logo, o fantasmagórico torna-se cada vez mais presente. Às 7 h50 do dia 18 de Julho de 2015, na rua Passos Manuel, a autora pretende fotografar a montra da "Dagol — o fabuloso mundo do vidro acrílico" (105). O catálogo da linha de acrílicos "Frost" contava, nessa altura, com doze cores diferentes e textualmente binomiais, como "aurora violet" ou "lemon sorbet." Hoje, aproximadamente quatro anos depois da primeira edição de Bandolim, o catálogo revelado poesia a partir do negativo da realidade conta com uma nova cor. O movimento que transporta a loja de acrílicos Dagol para o universo poético é o mesmo que devolve o poema à realidade prosaica da preservação arqueológica, a partir da qual o leitor pode re-conhecer a poesia enquanto forma de olhar. Em "Poema chinês" (166), a autora cria um negativo a partir de uma mise en scène temática: "Chá preto / arroz branco." A simplicidade do binómio oculta o número infinito de possibilidades de revelação/tradução deste negativo/texto em outros meios artísticos.

Nas considerações iniciais, sugeri a hipótese de Bandolim ser um livro iminentemente fotográfico e usei a imagem do "Barómetro" (143) para ilustrar a ambiguidade temperamental de um instrumento no qual consonância e dissonância são variavelmente constitutivas. Não cheguei, todavia, a realçar o modo fotográfico de representação desse poema: decalca um barómetro de parede, fixando na escrita a imagem textual do objeto. Polarizado entre “TEMPESTADE” e "TEMPO SECO," oscila entre expressões ambíguas como 
"G. CHUVA," "VARIÁVEL" e "BOM FIXO." A exploração da ambiguidade enquanto produto notável abre Bandolim à influência de meios artísticos diversos. Os mecanismos descritos, em particular os que envolvem a poética do significante, levam a que ronde fronteiras cinemáticas: "Podia realizar filmes só com a lista dos telefones e música" (49). Bandolim transpõe os limites aparentes da escrita poética. E muitas vezes fá-lo pondo-os em evidência, como se traduzissem a poesia que além deles se situa ou ainda que a poesia se situa além deles. Assim, o livro parece questionar a noção de poesia como forma de arte escrita e tangível, reformulando-a como matriz intangível de meios artísticos diversos. Além de "BOM FIXO," é isso que o desenho solar da capa parece anunciar. Trata-se de uma circunferência emanando oito raios, onde cada raio dá origem a novo sol com oito raios. O desenho tende para o infinito em todas as direções, mas representa essa tendência de forma contingente, tal como a fórmula do binómio de Newton: em vez de cobrir de sóis todo o espaço em branco, cinge-se à sugestão dessa possibilidade. É ainda composto por um elemento textual, que parece legendar a figura: "alcachofras." A planta é conhecida pela geometria irradiante dos seus capítulos florais e parece ser assim entendida como contingência literal do infinito.

Comecei por refletir sobre o título e serpenteei até ao desenho, mas também podia ter traçado a minha leitura do projeto de conjunto deste livro no sentido inverso. Tentei fazer soar, através dos dois elementos da capa, o cordoamento duplo que dá a este Bandolim de Adília Lopes um timbre característico: $2=1$ e $1=\infty$ !

\section{Obras citadas}

Barthes, Roland. Critique et vérité. Seuil. 1966.

—. Crítica e verdade. Tradução de Madalena da Cruz Ferreira, Edições 70, 2017. Houaiss, António, e Mauro de Salles Villar. Dicionário Houaiss da língua portuguesa. 3 vols. Temas \& Debates, 2003.

Eliot, T. S. "Tradition and the Individual Talent." 1919. Poetry Foundation, poetryfoundation.org/articles/69400/tradition-and-the-individual-talent.

"Frost, gama de acrílicos." Dagol, 2016, dagol.com/wp-content/uploads/2016/ 11/folheto-frost.pdf.

Lopes, Adília. Bandolim. Assírio \& Alvim, 2016. 
—. Estar em casa. Assírio \& Alvim, 2018.

—. Manhã. Assírio \& Alvim, 2015.

Pimenta, Alberto. O silêncio dos poetas. Cotovia, 2003.

Verlaine, Paul. “Art poétique." Poésie Française, poesie.webnet.fr/ lesgrandsclassiques/poemes/paul_verlaine/art_poetique. 